\title{
Factors Mediating Between Government Expenditure and Unemployment in Nigeria
}

\author{
Chike Henry Nwankwo', Amechi Henry Igweze ${ }^{2}$ \\ ${ }^{1}$ Department of Statistics, Nnamdi Azikiwe University, Awka, Nigeria \\ ${ }^{2}$ Department of Mathematics and Statistics, Delta State Polytechnic, Ogwashi-Uku, Nigeria \\ Email address: \\ chikeezeoke@yahoo.com (C. H. Nwabkwo), amaeze1@yahoo.com (A. H. Igweze)
}

\section{To cite this article:}

Chike Henry Nwankwo, Amechi Henry Igweze. Factors Mediating Between Government Expenditure and Unemployment in Nigeria. Science Journal of Applied Mathematics and Statistics. Vol. 4, No. 2, 2016, pp. 43-47. doi: 10.11648/j.sjams.20160402.14

Received: January 16, 2016; Accepted: February 8, 2016; Published: March 18, 2016

\begin{abstract}
The study seeks to find economic variables mediating between unemployment and government expenditure in Nigeria. The indirect effect was tested using the method of difference of coefficient. the findings shoe that only labour force population and inflation showed evidence of partial mediation, although their mediational (indirect) effect are not statistically significant as the P-values of the test of indirect effect are all greater than the level of significance, 0.05. Further studies are recommended to ascertain factors mediating upon government expenditure and unemployment in Nigeria other than economic variables already studied.
\end{abstract}

Keywords: Mediation, Government Expenditure, Unemployment, Economic Variables

\section{Introduction}

Unemployment is a very important issue that plays a crucial role in development of economies. Unemployment is described as the number of people in the labour force population that is actively looking for job. It Includes only those people who are willing to work, and are either unemployed or looking for jobs [1].

According to Tunah [2], some of the very common causes of unemployment in developing economies are the technological changes, demographic structure, economic conditions, production of electricity immigration from rural areas towards towns and cities. According to the author, economic variables are vital factor that affects unemployment, noting that theoretically a positive relation should exist among economic growth indicators and employment, or negative with unemployment.

CBO [3] states that persistent high unemployment has wide-ranging consequences. It places financial, psychological, and even physical strains on people who are unable to find work and on their families as well; it places budgetary pressures on the federal government and on state and local governments, as tax revenues decline and expenditures increase; and it results in a long-term erosion of skills that will reduce the nation's productivity and people's income in the future. In addition to its immediate and lasting effects on earnings and family finances, unemployment is also correlated with deteriorating mental and physical health and with increased mortality. A parent's job loss can lead to worse schooling outcomes for children and, ultimately, to worse labor market outcomes for those children once they become adults. In those and other ways, unemployment is costly for many households, and the adverse effects are probably worse for those unemployed for an extended period.

The persistent problem of unemployment engaged the attention of different Federal Government administration which resulted in employment generation programmes and policies targeted at the menace of unemployment in the Nigerian polity. Prominent among these programmes are the establishment of the National Directorate of Employment (NDE) in 1986 by the Babangida led administration and National Economic Empowerment and Development Strategy (NEEDS) by the Obansanjo led administration [4].

For many decades now, successive governments in Nigeria had adopted various policies to create jobs and reduce unemployment. In spite of these policies, unemployment has continued to rise unabated. This may suggest that there could be other factors mediating between government expenditures and unemployment in Nigeria. Thus, this study aims at 
ascertaining economic factors mediating upon unemployment in Nigeria, as the high level of unemployment in Nigeria is of great concern and need be mitigated, and one way of achieving this is through appropriate economic policies.

Often times, theory suggests that a third variable may improve understanding of the nature of the relationship between the two primary variables. The third variable considered a mediator, is hypothesized to be linked in a causal chain between the independent and dependent variables. In other words, the independent variable causes the mediator and the mediator causes the dependent variable. The search for intermediate causal variables is called mediation analysis.

Purpose of the Study

The purpose of this study includes:

1. To determine the variables mediating upon unemployment using Government expenditure (Gross National Expenditure) as independent variable.

2. To determine the type of mediation (full or partial) present in the proven cases in (1) above

\section{Literature Review}

Several studies have been carried out to determine the relationship between economic variables and unemployment in Nigeria. Some of such studies are reviewed.

Tunah [2] studied the macroeconomic variables which affects unemployment for Turkey. Quarterly data from 2000 to 2008 was used in the study. Augment Dickey Fuller test (ADF), Phillip-Perron test, Johansen's cointegration and granger causality techniques were used for analysis. The results of the study showed that there is a significant impact of real GDP, consumer price index and previous unemployment rate on the unemployment rate. Whereas real effective exchange rate has no impact on the unemployment.

Lui [5] studied the relationship between inflation and unemployment in a situation where inflation has differential outcomes on employed and unemployed. The result shows that the relationship between inflation and unemployment is either negative or positive which depend on goods \& labor market institutions. A higher rate of inflation increases workers' incentives to work $\&$ generates a negative effect on unemployment. On the other hand, inflation lowers a firm's return from creating job vacancies, thereby raising unemployment

Pallis [6] studied the relationship between inflation and unemployment in new European Union member states. The three variables employed are "the price deflator of gross domestic product at market prices (national currency; annual percentage change)" and "nominal compensation per employee; total economy (national currency; annual percentage change)" and "total employment rate (\%)". Nonlinear least square regression was employed in the study. The paper concludes that the application of common policies across economy may be questionable because of the different effect of these policies on inflation and unemployment

El-Agrody et al. [7] examined unemployment and its impact on the GDP in Egypt. Data was collected from the year 1994 to 2004. Linear regression analysis was applied. Variables used in the study were privatization, population, consumption expenditure, interest rates, exchange rates, technology, agricultural domestic product, real wage rates, and agricultural investment. The results showed that there is a significant positive impact of Egypt national unemployment, national investment, exchange rate and average per capita share of GDP on the volume of GDP. The results also highlighted privatization and increasing population as the main reasons of increasing unemployment. They recommended that privatization policies need to be revised and to reduce interest rates in order to lowering the agricultural unemployment.

Doğan [8] investigated the response of unemployment to selective macroeconomics shocks for the period of 2000: Q12010: Q1. It finds that positive shocks to growth, growth in export and inflation reduce unemployment. On the other hand, shocks to exchange rate, interbank interest rate and money supply increase unemployment. The the author states that the results are consistent with Phillips curve and Okun's Law suggestion. Namely, negative relationship between output and unemployment and positive relationship between unemployment and inflation are found.

\section{Research Methods}

The study employs mediation analysis. The analysis begins by testing for multicolinearity among the independent variables. This was accomplished with the use of variance Inflation Factor (VIF). The first step in meditational analysis is to establish that a relationship exist between Gross National Expenditure (GNE) as the independent variable and the dependent variable, unemployment rate using a regression linear model. This is known as path c. Next is to conduct a regression analysis with the other variables predicting the dependent variable. This is known as path $b$. thirdly, conduct a regression analysis with the independent and other variables predicting the dependent variable, known as partial effect model. The data used for the study are: Unemployment rate as the dependent variable(Y) and Gross National Expenditure (X). The suspected mediator variables are: Electricity consumption per capita $\left(Z_{1}\right)$, Gross Domestic Product $\left(Z_{2}\right)$, Labour force population $(16-64 y r s)\left(Z_{3}\right)$, Crude oil production $\left(Z_{4}\right)$, Interest rate $\left(Z_{5}\right)$, Inflation $\left(Z_{6}\right)$ and Crude oil price $\left(Z_{7}\right)$.

\subsection{Indirect Effect}

The indirect effect measures the extent to which the dependent variable changes when the independent variable is held fixed; and the mediator variable changes by the amount it would have changed had the independent variable increased by one unit.

Judd \& Kenny [9] Process Analysis outlined a procedure for calculating indirect effect by computing the difference between two regression coefficients. Equations (1) and (2) below are required to do this. 


$$
\begin{aligned}
& \mathrm{Y}=\mathrm{c}_{0}+\mathrm{cX}+\mathrm{e}_{1}, \\
& \mathrm{Y}=\mathrm{c}^{\prime}+\mathrm{c}^{\prime} \mathrm{X}+\mathrm{bZ}+\mathrm{e}_{3}
\end{aligned}
$$

The indirect effect is obtained by subtracting coefficient for $\mathrm{X}$ in equation (2) from the coefficient of $\mathrm{X}$ in equation (1): that is

$$
b_{\text {indirect }}=c-c^{\prime}
$$

\subsection{Test of Significance of the Indirect Effect}

A test of significance of the indirect effect can be constructed using a ratio of the indirect coefficient to its standard error. The tests of indirect effect is given as:

$$
Z_{\text {indirect }}=\frac{b_{\text {indirect }}}{S_{\left(b_{\text {indirect }}\right)}}
$$

Where

$$
S_{\left(b_{\text {indirect }}\right)}=\sqrt{b^{2} S_{a}^{2}+a^{2} S_{b}^{2}}
$$

Hypotheses

The required hypotheses are:

$$
\begin{gathered}
\mathrm{H}_{0}: \mathrm{C}-\mathrm{C}^{\prime}=0 \\
\mathrm{Vs} \\
\mathrm{H}_{1}: \mathrm{C}-\mathrm{C}^{\prime} \neq 0
\end{gathered}
$$

At $5 \%$ level of significance.

\section{Result and Discussion of Findings}

\subsection{Testing for Multicolinearity}

The SPSS software was used to compute the $\mathrm{VIF}_{\mathrm{k}}$. The first colinearity test conducted showed that $Z_{2}$ has a $V_{I F}$ greater than 10. Hence it was deleted and the VIF recalculated. The second $\mathrm{VIF}_{\mathrm{k}}$ result is presented below.

Table 1. Colinearity statistics ${ }^{a}$.

\begin{tabular}{llll}
\hline \multirow{2}{*}{ Model } & \multicolumn{3}{l}{ Collinearity Statistics } \\
\cline { 3 - 4 } & & Tolerance & VIF \\
\hline \multirow{4}{*}{1} & Z1 & .224 & 4.460 \\
& Z3 & .507 & 1.972 \\
& Z4 & .208 & 4.812 \\
& Z5 & .395 & 2.530 \\
& Z6 & .667 & 1.500 \\
Z7 & .204 & 4.895 \\
\hline
\end{tabular}

a. Dependent Variable: Y

From table 1 it is observed that removal of Domestic Product $\left(Z_{2}\right)$ alone further reduced the VIF values of the other variables to values below 10 which is an acceptable VIF value

\subsection{Analysis of Path $c$}

The regression model of path $\mathrm{c}$ is given as:

$$
\mathrm{Y}=5.11+6.13 \times 10^{-13} \mathrm{X}
$$

The significance of the variables are accessed by comparing the level of significance $(\alpha=0.05)$ with the $p$ value. Comparing the p-value $(0.00)$ with the level of significance shows that significant relationships exist between the dependent (unemployment rate) and independent variable (Gross national Expenditure).

\subsection{Analysis of Path a}

There are six variables suspected to mediate between unemployment rate and Gross national Expenditure, hence six models of path a are required of which the interest are in the coefficients of $\mathrm{X}$, (a). The coefficients of paths a are given below.

Table 2. Coefficients of Path a.

\begin{tabular}{llll}
\hline \multicolumn{5}{c}{$\mathbf{Z}=\mathbf{a}_{\mathbf{0}}+\mathbf{a}_{\mathbf{1}} \mathbf{X}$ (path $\left.\mathbf{a}\right)$} \\
\hline & $\mathbf{a}_{\mathbf{1}}$ & Sa & PV(a) \\
\hline$Z_{1}$ & $2.118 \mathrm{E}-12$ & 0.000 & 0.000 \\
$Z_{3}$ & $1.865 \mathrm{E}-14$ & 0.000 & 0.101 \\
$Z_{4}$ & $2.68 \mathrm{E}-11$ & 0.000 & 0.000 \\
$Z_{5}$ & $2.571 \mathrm{E}-14$ & 0.000 & 0.767 \\
$Z_{6}$ & $-5.482 \mathrm{E}-13$ & 0.000 & 0.045 \\
$Z_{7}$ & $2.064 \mathrm{E}-12$ & 0.000 & 0.000 \\
\hline
\end{tabular}

Here again, we ascertain the significance of $\mathrm{X}$ when predicting the suspected mediator variables by comparing the p-values [PV (a)] with the significance level. In the analysis of path $a$, the independent variable was found not to significantly predict interest rate $\left(Z_{5}\right)$, hence suggesting that

\begin{tabular}{|c|c|c|c|}
\hline \multicolumn{4}{|c|}{$Y=b_{0}+b_{1} Z($ path $b)$} \\
\hline & $\mathbf{b}_{1}$ & Sb & PV(b) \\
\hline$Z_{1}$ & 0.211 & 0.034 & 0.000 \\
\hline $\mathrm{Z}_{3}$ & 4.214 & 1.677 & 0.017 \\
\hline $\mathrm{Z}_{4}$ & 0.012 & 0.002 & 0.000 \\
\hline $\mathrm{Z}_{5}$ & 0.082 & 0.245 & 0.740 \\
\hline $\mathrm{Z}_{6}$ & -0.183 & 0.065 & 0.008 \\
\hline $\mathrm{Z}_{7}$ & 0.243 & 0.032 & 0.000 \\
\hline
\end{tabular}
interest rate cannot be mediator variable.

\subsection{Analysis of Path $b$}

Similarly, we ascertain the significance of the suspected mediator variables $\left(Z_{i} ; i=1,2, \ldots, 7\right)$ when predicting the dependent variable (unemployment rate) by comparing the $\mathrm{p}$ values [PV (b)] with the significance level $(\alpha=0.05)$, see table 3 below.

Table 3. Coefficients of $Z$ in path $b$.

It was also observed that only interest rate $\left(Z_{5}\right)$ does not significantly predict the dependent variable as the p-value is greater than the level of significance. The non significance of interest rate further affirms that interest rate cannot be a mediator, hence it is deleted.

\subsection{Partial Effect Model}

The table below presents the coefficients of the independent variable (Government expenditure) and the ith mediator variables when predicting unemployment rate. The 
coefficients of $\mathrm{X}$ and $\mathrm{Z}$ are seen in the table 4.

Table 4. Coefficients of X and $Z$ in the partial effect model.

\begin{tabular}{llllllll}
\hline \multicolumn{7}{c}{$Y=\mathbf{a}+\mathbf{C}^{\prime} \mathbf{X}+\mathbf{b Z}$ (partial effect) } \\
\hline & $\mathbf{C}$ & $\mathbf{C}^{\prime}$ & std err & $\mathbf{P V}\left(\mathbf{C}^{\prime}\right)$ & $\mathbf{b}$ & std err & $\mathbf{P V ( b )}$ \\
\hline $\mathrm{Z}_{1}$ & $6.13 \times 10^{-13}$ & $8 \times 10^{-13}$ & 0.00 & 0.00 & -0.088 & 0.044 & 0.056 \\
$\mathrm{Z}_{3}$ & $6.13 \times 10^{-13}$ & $5.83 \times 10^{-13}$ & 0.00 & 0.00 & 1.654 & 0.765 & 0.038 \\
$\mathrm{Z}_{4}$ & $6.13 \times 10^{-13}$ & $5.98 \times 10^{-13}$ & 0.00 & 0.00 & 0.001 & 0.002 & 0.779 \\
$\mathrm{Z}_{6}$ & $6.13 \times 10^{-13}$ & $5.77 \times 10^{-13}$ & 0.00 & 0.00 & -0.066 & 0.031 & 0.039 \\
$\mathrm{Z}_{7}$ & $6.13 \times 10^{-13}$ & $7.7 \times 10^{-13}$ & 0.00 & 0.00 & -0.076 & 0.059 & 0.208 \\
\hline
\end{tabular}

From table 4 it is observed that the coefficients of $X$ in the partial effect model for the various suspected mediators $\left(Z_{1}\right.$, $Z_{3}, Z_{4}, Z_{6}$ and $Z_{7}$ ) are all less that the coefficient of $X$ in path $\mathrm{C}$ (i.e $\mathrm{C}^{\prime}<\mathrm{C}$ ). However only the coefficients of labour force population $\left(\mathrm{Z}_{3}\right)$ and inflation $\left(\mathrm{Z}_{6}\right)$ are significant in the partial effect model at $5 \%$ level of significance, hence they are confirmed as mediators.

\subsection{Types of Mediation}

The type of mediation that exist, solely depends on the total effect model and partial effect model in equation. When path $\mathrm{C}$ is significant while $\mathrm{C}^{\prime}$ is non-significant $\left(\mathrm{C}^{\prime}=0\right)$ and $\mathrm{b}$ is still significant then there is evidence of full mediation. Partial mediation occurs when path $\mathrm{C}$ is significant while $\mathrm{C}^{\prime}$ is greatly reduced (i.e $\mathrm{C}^{\prime}<\mathrm{C}$ ) and $\mathrm{b}$ is still significant. Otherwise, there is no mediation.
Table 5. Type of mediation.

\begin{tabular}{llllllll}
\hline \multicolumn{7}{l}{$\mathbf{Y}=\mathbf{a}+\mathbf{C}^{\prime} \mathbf{X}+\mathbf{b Z}$ (partial effect) } \\
\hline & $\mathbf{C}^{\prime}$ & std err & $\mathbf{P V}\left(\mathbf{C}^{\prime}\right)$ & $\mathbf{b}$ & std err & $\mathbf{P V ( b )}$ & Nature \\
\hline $\mathrm{Z}_{3}$ & $5.83 \times 10^{-13}$ & 0.00 & 0.00 & 1.654 & 0.765 & 0.038 & Partial \\
$\mathrm{Z}_{6}$ & $5.77 \times 10^{-13}$ & 0.00 & 0.00 & -0.066 & 0.031 & 0.039 & Partial \\
\hline
\end{tabular}

A comparison of the coefficient of $\mathrm{X}$ in path $\mathrm{C}$ and the coefficients of $\mathrm{X}$ when fitted alongside each of the mediator variables (partial effect model) will help in determining the type of mediation.

The p-values in table 4 show that the coefficients of $Z_{3}$ and $Z_{6}$ in the partial effect model are still significant even though they are reduced. This shows evidence of partial mediation.

\subsection{Indirect Effect}

The method of difference of coefficient, C- $\mathrm{C}^{\prime}$ is employed in the calculation of indirect effect. This is the difference in the coefficient of $X$ in path $C$ and coefficient of $X$ in partial effect model.

Table 6. Indirect Effects.

\begin{tabular}{llll}
\hline $\mathbf{Z}$ & $\mathbf{C}$ & $\mathbf{C}^{\prime}$ & $\mathbf{C}^{\prime} \mathbf{C}^{\prime}$ \\
\hline$Z_{3}$ & $6.134 \times 10^{-13}$ & $5.825 \times 10^{-13}$ & $3.09 \times 10^{-14}$ \\
$Z_{6}$ & $6.134 \times 10^{-13}$ & $5.771 \times 10^{-13}$ & $3.63 \times 10^{-14}$ \\
\hline
\end{tabular}

The values of the effect sizes are presented in table 6 . Hence the significance of the effect size is tested for labour force population and inflation.

Table 7. Standard Errors of coefficients of mediators.

\begin{tabular}{|c|c|c|c|c|c|c|c|c|c|c|c|}
\hline $\mathbf{M}$ & $\mathrm{C}$ & $\mathrm{C}^{\prime}$ & $\mathbf{a}_{\mathbf{i}}$ & $\mathbf{b}_{\mathrm{i}}$ & $S_{a}$ & $S_{b}$ & $\mathbf{S}_{\mathrm{a}}{ }^{2}$ & $\mathrm{~S}_{\mathrm{b}}{ }^{2}$ & $\mathbf{a}_{1}^{2} \mathbf{S}_{\mathrm{b}}^{2}$ & $\mathbf{b}_{1}{ }^{2} \mathbf{S}_{\mathrm{a}}{ }^{2}$ & $S_{a}{ }^{2} S_{b}{ }^{2}$ \\
\hline $\mathrm{Z}_{3}$ & $6.13 \times 10^{-13}$ & $5.825 \times 10^{-13}$ & $1.87 \times 10^{-14}$ & $4.42 \times 10^{-13}$ & 0.00 & 1.677 & 0.000 & 2.812 & $9.78 \times 10^{-28}$ & 0 & 0 \\
\hline $\mathrm{Z}_{6}$ & $6.13 \times 10^{-13}$ & $5.771 \times 10^{-13}$ & $5.48 \times 10^{-13}$ & -0.066 & 0.00 & 0.065 & 0.000 & 0.0042 & $1.27 \times 10^{-27}$ & 0 & 0 \\
\hline
\end{tabular}

The standard error for the effect size is given as:

$$
S_{\left(b_{\text {indirect }}\right)}=\sqrt{b^{2} S_{a}^{2}+a^{2} S_{b}^{2}}
$$

Hence the standard error for labour force population $\left(Z_{3}\right)$ is calculated as:

$$
\begin{aligned}
& S_{3\left(b_{\text {indirect }}\right)}=\sqrt{\left(4.4 X 10^{-13}\right)^{2} X(0)^{2}+\left(1.87 X 10^{-14}\right)^{2}(2.812)} \\
& =\sqrt{0+9.78 X 10^{-28}}=\sqrt{9.78 \times 10^{-28}}=3.13 \times 10^{-14}
\end{aligned}
$$

Where $S_{3\left(b_{\text {indirect }}\right)}$ is the standard error of the indirect effect of labour force population $\left(Z_{3}\right)$

Similarly the standard error for the effect size of inflation $\left(Z_{6}\right)$ is given as

$$
\begin{aligned}
S_{6_{\left(b_{\text {indirect }}\right)}} & =\sqrt{(-0.066)^{2} X(0)^{2}+\left(5.48 \times 10^{-13}\right)^{2}(0.0042)} \\
& =\sqrt{1.27 \times 10^{-27}}=3.56 \times 10^{-14}
\end{aligned}
$$

\subsection{Test of Significance of Indirect Effect}

The Sobels tests of indirect effect [10] for the various mediators are presented below

$$
Z_{\text {indirect }}=\frac{b_{\text {indirect }}}{S_{\left(b_{\text {indirect }}\right)}}
$$

For test of indirect effect of labour force population $\left(Z_{3}\right)$ and inflation $\left(\mathrm{Z}_{6}\right)$ we have

$$
\begin{gathered}
Z_{3(\text { indirect })}=\frac{b_{4(\text { indirect })}}{S_{3\left(b_{\text {indirect }}\right)}} \\
Z_{3(\text { indirect })}=\frac{3.09 \times 10^{-14}}{3.136 \times 10^{-14}}=0.9872 \\
Z_{6(\text { indirect })}=\frac{3.63 \times 10^{-14}}{3.564 \times 10^{-14}}=1.019 ;
\end{gathered}
$$

Table 8. Tests of Indirect Effects (C-C').

\begin{tabular}{lllll}
\hline & Effects & Sobel & & \\
\hline $\mathbf{Z}$ & C-C & Std Error & Zcal & P-value \\
\hline$Z_{3}$ & $3.09 \times 10^{-14}$ & $3.14 \times 10^{-14}$ & 0.986 & 0.324 \\
$Z_{6}$ & $3.63 \times 10^{-14}$ & $3.56 \times 10^{-14}$ & 1.016 & 0.31 \\
\hline
\end{tabular}

The Sobels test of indirect effect shows that the effect sizes for labour force population and inflation are not significant at $5 \%$ level of significance 


\section{Summary of Findings}

The study seeks to find economic variables mediating between unemployment and government expenditure in Nigeria. The indirect effect was tested using the method of difference of coefficient. The following are the findings:

In determine economic variables that mediate upon government expenditure and unemployment in Nigeria, only labour force population and inflation showed evidence of mediation, although their mediational (indirect) effect are not statistically significant as the P-values of the test of indirect effect are all greater than the level of significance, 0.05 .

Although not statistically significant, labour force population and inflation were respectively found to have trace of partial mediation as $\mathrm{C}^{\prime}$ were less than $\mathrm{C}$.

\section{Conclusion and Recommendation}

The results of analysis conducted in this study have been presented. Hence the following conclusions:

Combinations of increasing labour force population and high inflation rate were found to mediate upon government expenditure and unemployment in Nigeria. In economic views, increase in labour force population without proportionate increase in job creation directly increases unemployment rate in a country. Again high rate of inflation, which is persistent increase in the prices of goods and services creates additional costs of labour and thus indirectly reducing the number of man power that can be demanded for.

The partial mediation observed for labour force population and inflation suggests that they are not the only variables accountable for unemployment in Nigeria. So there could be other variable(s) mediating upon government expenditures especially on capital projects and unemployment rate in Nigeria.

Based on the findings in this study, further studies may be recommended to ascertain factors mediating upon government expenditure and unemployment in Nigeria other than economic variables already studied.

\section{References}

[1] Asif, K (2013). Factors Effecting Unemployment: A Cross Country Analysis. International Journal of Academic Research in Business and Social Sciences, Vol. 3(1).

[2] Tunah, H. (2010). The Analysis of Unemployment in Turkey: Some Empirical Evidence Using Co integration Test. European Journal of Social Sciences, 18 (1), 18-38.

[3] Congress Of The United States Congressional Budget Office, CBO (2012) Understanding and Responding to Persistently High Unemployment.

[4] Mbah, S. A, \& Agu, O. C (2013). The Effectiveness of Government Employment Policies in Nigeria, IOSR Journal Of Humanities And Social Science Vol. 12(3).

[5] Lui, L. Q. (2009). Inflation and Unemployment: The roles of goos and labor market institution. 131.

[6] Pallis, D. (2006). The trade off between inflation and unemployment in new European Union member-states. International Research Journal Of Finance and Economics (1), $81-97$

[7] El-Agrody, N. M., Othman, A. Z., \& Hassan, M. B.-D. (2010). Economic Study of Unemployment in Egypt and Impacts on GDP. Nature and Science, 8 (10), 102-111.

[8] Doğan, T. T (2012). Macroeconomic Variables and Unemployment: The Case of Turkey. International Journal of Economics and Financial Issues Vol. 2(1).

[9] Judd CM, Kenny DA. (1981)Process analysis: Estimating mediation in treatment evaluations. Evaluation. Review. (5): 602-619.

[10] Sobel, M. E. (1982). Asymptotic Confidence Intervals For Indirect Effects In Structural equations models. In S. Leinhart (Ed.), Sociological methodology 1982 (pp. 290-312). San Francisco: Jossey-Bass. 